\title{
0 sentido da participação para o assistente social representante do gestor nos Conselhos de Assistência Social
}

\author{
The participation conception for the social worker manager representative in the Social \\ Assistance Councils
}

\section{Resumo:}

0 trabalho apresenta uma abordagem acerca da concepção de participação emitida pelos profissionais que representam o gestor nos Conselhos M unicipais de Assistência Social. 0 texto segue uma perspectiva sócio-histórica da participação nas políticas sociais, sustentado em referências da literatura sobre o tema. Trata-se de um estudo bibliográfico, documental e com aplicação de questionário. 0 texto inicia com reflexões sobre algumas tendências teórico-políticas da participação que se expressam nos colegiados participativos após 1988. Essa pesquisa foi aplicada à 14 profissionais de Serviço Social que representavam o segmento do gestor em municípios do estado de Santa Catarina. 0 sentido de participação indicado pelos profissionais tem ênfase na lógica de fazer parte, de emitir opinião, de fazer troca e secundariamente tem o sentido de democratizar a relação Estado e sociedade e garantir os direitos sociais.

Palavras- chave: Participação. Conselhos. Serviço social. Exercício profissional. Política de assistência social.

\begin{abstract}
:
This paper presents an approach about the participation conception issued by professionals who represent the manager in the Municipal Councils of Social Assistance. The text follows a sociohistorical perspective of participation in social policies, supported by references of the literature on the subject. This is a bibliographic, documentary and questionnaire application. The text begins with reflections on some theoretical-political tendencies of participation that are expressed in participatory colleges after 1988. This research was applied to 14 Social Service professionals who represented the segment of manager in municipalities in the state of Santa Catarina. The sense of participation indicated by the professionals emphasizes the logic of being part, of expressing opinion, of making exchange and secondarily has the sense to democratize the relation State and society and guarantee social rights.
\end{abstract}

Keywords: Participation. Councils. Social servisse. Professional practice. Social welfare policy.

\section{Introdução}

A Constituição Federal de 1988 foi resultado de diversas lutas e embates ocorridos no período de redemocratização na sociedade brasileira. Particularmente para as políticas sociais, o texto constitucional representou uma modernização política que se vincula à democracia popular e participativa, tendo em vista que os direitos sociais se pautam pela

\footnotetext{
* Graduada em Serviço Social pela Universidade Católica de Pelotas-RS (UCPEL) e Mestra em Serviço Social pela Universidade Federal de Santa Catarina (UFSC).

** Doutora em Serviço Social pela Universidade Federal de Pernambuco (UFPE). Professora do Departamento de Serviço Social e do Programa de Pós-Graduação em Serviço Social da Universidade Federal de Santa Catarina.
} 
participação da sociedade. Sendo assim, é a partir desse arcabouço legal que a participação passa a constituir-se como um direito social, no qual a sociedade integra o processo de formulação e controle das políticas sociais nos três níveis de governo.

As leis infraconstitucionais que regulamentaram cada política setorial (assistência social, criança e adolescente, saúde, etc) institucionalizaram os espaços de participação: os conselhos e as conferências ${ }^{1}$. Os conselhos com composição paritária atuam na elaboração, deliberação, avaliação, fiscalização e reúnem-se com periodicidade mensal. Apesar de serem considerados avanços democráticos, essas três décadas de existência revelam que tais colegiados são perpassados por contradições e disputas de interesses particulares ou corporativos, já que podem se constituir em espaços de legitimação do poder dominante em detrimento da representação do interesse público e coletivo.

Embora se identifique os conselhos como espaços de alargamento das fronteiras tradicionais do Estado para segmentos antes excluídos de qualquer tipo de participação, também verificamos que os mesmos estão reproduzindo elementos tradicionais de nossa cultura política.

Esses canais deliberativos também são espaços onde atuam diversos profissionais, sendo 0 assistente social um destes técnicos. Esse profissional que atua diretamente com as expressões da questão social tem a oportunidade de inserir-se nos espaços de participação, priorizando o processo de publicização e socialização das informações em consonância com o Projeto Ético-Político do Serviço Social. Com isso, os conselhos também se constituem em espaços de atuação e exercício profissional do assistente social, tendo em vista que este profissional é designado ou eleito e pode representar a sociedade civil (prestadores de serviço, trabalhadores ou usuários) ou o gestor.

Além de conselheiro o assistente social ainda pode desempenhar outras funções neste colegiado deliberativo, desde assessor, secretário executivo, capacitador, pesquisador e até articulador de políticas sociais. Participar desses espaços constitui uma das competências do assistente social que está disposta em sua Lei de Regulamentação da Profissão de 1993 (LEI n 8662/93, Art. 4), onde o compete elaborar, implementar e avaliar

\footnotetext{
${ }^{1}$ Vale ressaltar que os conselhos de direitos e políticas sociais não são os únicos espaços de participação e controle social. Temos como exemplo as conferências, que conforme preconiza a NOB/SUAS (BRASIL, 2005), são instâncias que têm por atribuições a avaliação da política de Assistência Social e a definição de diretrizes para 0 aprimoramento do SUAS, ocorrendo no âmbito da União, dos Estados, do Distrito Federal e dos Municípios. Além disso, temos ainda o referendo, o plebiscito, a iniciativa popular, audiências públicas, orçamento participativo, fóruns de políticas públicas, etc. Entretanto, esse texto irá ressaltar o papel da participação nos conselhos.
} 
políticas sociais junto à órgãos de administração pública, além de avaliar programas e projetos com participação da sociedade civil.

Também vale ressaltar que nesse espaço de disputa política se expressam algumas tendências sobre 0 tema da participação. Essas tendências possuem o sentido de reproduzir os traços da cultura política brasileira e ao mesmo tempo alargar os limites do Estado para segmentos sociais, antes sem qualquer condição de acesso aos espaços de decisão sobre as políticas públicas.

A partir desse contexto 0 artigo propõe-se a apresentar a concepção de participação emitida pelos assistentes sociais que representam 0 gestor nos Conselhos Municipais de Assistência Social ${ }^{2}$. Essa pesquisa foi de natureza qualitativa, tendo como método de coleta de dados a aplicação de questionários, acompanhada da revisão da literatura e documentos públicos do tema.

Para a realização do estudo foram aplicados questionários para assistentes sociais que eram, em 2014, representantes do gestor em Conselhos M unicipais de Assistência Social - CM AS em Santa Catarina. Foram enviados 25 questionários e destes, retornaram 14 de 11 municípios. Estes municípios representam cinco regiões do estado: Grande Florianópolis (Florianópolis, São José, Palhoça e Santo Amaro da Imperatriz), Serrana (Lages), Oeste (Chapecó, Concórdia e Caçador), Norte (Joinville) e Vale do Itajaí (Brusque e Bombinhas).

0 presente trabalho encontra-se estruturado em três itens. 0 primeiro deles descreve o papel da participação nos conselhos de direitos e políticas sociais, com reflexões sobre o sentido da participação nos colegiados institucionalizados de políticas sociais. $\mathrm{Na}$ sequência, será apresentada uma abordagem sobre a atuação do Serviço Social nos espaços de participação, em especial como representante do gestor, no contexto dos Conselhos de Assistência Social. Por fim, serão trazidos os conceitos de participação apontados pelos profissionais de Serviço Social que participaram da pesquisa e com análises sobre o seu significado.

\footnotetext{
${ }^{2} O$ projeto desta pesquisa foi encaminhado ao Comitê de Ética e Pesquisa em Seres Humanos da Universidade Federal de Santa Catarina (CEPSH/UFSC) e aprovado em 25 de agosto de 2014, sob o número de protocolo: 32994214.2.0000.0121. Deste estudo resultou a dissertação intitulada "Os assistentes sociais nos Conselhos de Assistência Social como representantes do gestor", que tinha como objetivo geral conhecer e analisar o exercício profissional do assistente social como representante do gestor nos CMAS nos municípios do Estado de Santa Catarina. (M ACHADO, 2015).
} 


\section{0 sentido da Participação nos Conselhos de Direitos e Políticas Sociais}

A Carta Constitucional de 1988 trouxe novas perspectivas para as políticas sociais brasileiras. Até então as transformações na estrutura política e econômica vigente, aconteciam por revoluções passivas ou um reformismo pelo alto, onde as classes populares não eram protagonistas. Perpetuou-se no país o caráter e os traços conservadores da velha ordem dominante (COUTINHO, 2008).

0 reconhecimento dos direitos sociais e a institucionalização dos espaços de participação social, por meio dos Conselhos e Conferências, representou uma tentativa de dar protagonismo às classes populares para decidir, elaborar, fiscalizar e avaliar a execução das políticas sociais. Em certa medida, as Conferências e os Conselhos podem ser considerados espaços de democracia direta e um lócus no qual a sociedade civil e o órgão gestor dividem (ou deveriam dividir), a responsabilidade sobre as decisões a serem tomadas referentes às políticas sociais. Em geral, tais colegiados possuem caráter paritário e deliberativo e tem atuação nas três esferas de governo, tendo como base a descentralização político-administrativa.

Os Conselhos, dada sua heterogênea composição, são permeados por disputas, conflitos de interesse, por silenciamentos e podem tornar-se mecanismos de legitimação do poder dominante, já que os interesses que circulam em seu interior não são homogêneos. Apesar de retoricamente se constituírem como espaços democráticos, podem surgir articulações entre os diferentes segmentos que se vinculam aos "métodos clientelistas com maior ou menor sutileza, até regulamentações que não respeitam a legislação" (BEHRING; BOSCHETTI, 2006, p. 183). Outro obstáculo apontado pelas autoras é "a excessiva fragmentação e setorialização das políticas, o que dificulta a ocupação de espaços, principalmente por parte dos movimentos sociais e usuários" (BEHRING; BOSCHETTI, 2006, p. 183).

As políticas sociais são fruto de reivindicações, principalmente trabalhistas e se constituem ainda como o "instrumento através do qual se materializam os direitos sociais" (COUTINHO, 2008, p. 65). Elas possuem uma dimensão pública e com isso, "como todos os âmbitos da vida social, também a esfera das políticas sociais é determinada pela luta de classes", ressalta 0 autor (COUTINHO, 2008, p. 65). 
A democracia, para que se realize na sociedade brasileira, segundo Coutinho (2008, p. 153), necessita que as massas excluídas passem de coadjuvantes à protagonistas no processo social. Em seu entendimento, a democracia só acontecerá para as grandes massas se estas "forem capazes de se organizar, de expressar seus anseios e de obter efetivamente conquistas sociais, culturais e políticas no quadro de uma institucionalidade em permanente expansão" (COUTINHO, 2008, p. 153).

Para o desenvolvimento desse texto, o nosso entendimento de participação significa socializar o poder político e a riqueza socialmente produzida. A participação discutida neste trabalho não é apenas uma relação individual, mas diz respeito a uma política social, as decisões de um governo para atender necessidades sociais coletivas de forma a não privilegiar segmentos, a não ser por necessidades de equidade.

Os espaços de participação social que aqui tratamos devem ter o objetivo de discutir como a riqueza socialmente produzida (transformada em serviços públicos) pode atender às necessidades sociais (PAIVA; CARRARO; ROCHA, 2012). Além disso, a participação, considerada a partir de um processo de socialização da política e do poder de decisão política, deve ter como objetivo a luta pela efetivação e garantia de direitos da classe trabalhadora. 0 fato desses direitos estarem presentes na Constituição não tem significado na realidade brasileira, uma garantia de que serão realmente efetivados. Entretanto concordamos com Coutinho (2008, p. 65) que "é muito importante assegurar o seu reconhecimento legal, já que isso facilita a luta para torná-los efetivamente um dever do Estado".

A cultura política brasileira arraigada na submissão e concessão deixou heranças e a característica de país subordinado ainda se mantém. Entretanto, movimentos organizados tiveram papel relevante na implementação de direitos sociais e políticos. Entre estes direitos encontra-se a institucionalização de espaços participativos onde a sociedade tem a possibilidade de participar das decisões políticas diretamente ou através de seus representantes.

Esses canais deliberativos, mesmo institucionalizados e colocados no limite da burocracia estatal, nos últimos anos, vêm de alguma forma alargando os limites do Estado. Sujeitos sociais, historicamente excluídos das decisões públicas participam dos processos de proposições, fiscalização e avaliação das políticas públicas. Ainda que se apontem muitas contradições e se verifique a reprodução de elementos da nossa cultura política 
conservadora é inegável o avanço democrático que estes colegiados estão proporcionando. (KRÜGER, 2012).

Contudo, essa possibilidade jurídico-formal da participação nas políticas sociais tem promovido certa socialização da política, mas não a socialização do poder de decisão política, e, tampouco, uma apropriação social das estruturas de poder dos governos e do Estado. (KRÜGER; OLIVEIRA, 2018). No entanto, não podemos negar que os Conselhos e Conferências levaram o debate das políticas sociais setoriais para o interior do país e à segmentos sociais que nunca antes colocaram suas necessidades básicas na pauta do poder público.

O ganho histórico, civilizacional e de radicalidade democrática que representou 0 reconhecimento formal da participação popular para a deliberação das políticas sociais, não tem tido na gestão dos diferentes governos este sentido. Não temos visto governos e gestores de políticas sociais negarem este princípio constitucional, mas nos seus discursos e documentos a participação vem sofrendo um transformismo. 0 caráter deliberativo e fiscalizador dos espaços institucionais de participação vêm sendo progressivamente metamorfoseado e ganhando um sentido de parceria, de espaço de consulta, de colaboração, de ouvidoria e de mesa de diálogo social (BRASIL, 2014).

Com este transformismo, os espaços colegiados de participação tornaram-se mais burocráticos e perderam o caráter fiscalizador e propositivo (antes mesmo de conquistar efetivamente este caráter), predominando posturas aliancistas de cooperação, de solidariedade e de consenso que subalternizam os interesses do trabalho em prol do bem comum, do progresso, da justiça social, da governabilidade e da modernização ${ }^{3}$. As pautas desses espaços parecem ser cada vez mais setoriais e locais, com toda relevância que esses temas possuem, mas o caráter conflitivo e de disputas pela direção política e econômica dos serviços públicos apequenou-se (KRÜGER; OLIVEIRA, 2018).

Longe de serem retilíneos, estes espaços de participação institucionalizados, conforme evidenciamos, mesclam os ganhos e contradições. E procurando compreender 0 sentido de participação nas políticas sociais vimos que há diferentes maneiras de definir a

\footnotetext{
${ }^{3}$ A título de exemplo, temos a Política Nacional de Participação Social - PNPS e o Sistema Nacional de Participação Social - SNPS (Decreto № 8.243 de 23 de maio de 2014), que ainda assim, a presidência da República não conseguiu sua aprovação no Congresso Nacional, pois teve seus efeitos sustados pelo Decreto Legislativo: 147/2014 (CÂM ARA DOS DEPUTADOS, 2014a). No momento, está em tramitação no Senado um projeto de decreto legislativo: PDC 1491/2014 (CÂM ARA DOS DEPUTADOS, 2014b) que susta a aplicação do Decreto no 8.243 de 2014 (ALM EIDA, 2017).
} 
participação e inúmeras possibilidades e formas de expressar e organizar, colocando dificuldades de abrigá-la num marco teórico ou político. Mas nosso texto foi guiado por um entendimento de que realizar a política social com a participação de vários segmentos da sociedade civil, dos trabalhadores e dos prestadores de serviços do setor privado e filantrópico, é uma escolha e uma decisão política. Esta escolha política está longe de ser linear e isenta de conflitos.

Segundo Paiva, Rocha e Carraro (2012, p. 277), a participação popular deve buscar uma "transformação realmente anticapitalista". Quando fazem referência a essa transformação, afirmam que não se trata de criar ilusões como, por exemplo, que esse será o caminho de superar "o atual estado das coisas". As autoras não negam os espaços que foram firmados pelas lutas dos trabalhadores (como os sindicatos, movimentos, Conselhos, entre outros) e nem "o direito de se organizar em grupos, entidades e movimentos reivindicatórios". Para as autoras Paiva, Rocha e Carraro (2012, p. 277):

Trata-se de, pois, de ampliar e qualificar os espaços existentes, fomentar a criação de novos espaços, buscar uma razão de política pública cuja construção, a partir do protagonismo popular, possa garantir a participação das massas, no intuito de elevar a democracia realmente existente, a níveis contestadores e revolucionários.

As autoras não se opõem aos espaços participativos democráticos existentes, porém defendem a ideia de que estes necessitam ser qualificados e ampliados em direção à outra ordem societária. Esses espaços devem priorizar o protagonismo popular e dotar 0 povo de poder, ou seja, existe a necessidade de as políticas sociais serem construídas a partir de baixo, ou seja, a partir da participação popular. (PAIVA; ROCHA; CARRARO, 2012, p. 277).

$M$ as mencionamos um alerta sobre os canais de participação tendo em vista que: "são neutralizáveis e/ou assimiláveis pela estrutura econômica capitalista, uma vez que é de sua natureza, nas incidências sobre a instância política, interpor mediações e hierarquias entre representantes e representados" (NETTO, 1990, p. 88). Por esses motivos, o autor considera a necessidade de se operar "a socialização da economia e a socialização da política (do poder político), [...] tendo como estratégia] a imediata extensão de novos direitos de participação social real a classes e grupos sociais até então de fato excluídos ou marginalizados" (NETTO, 1990, 1990, p. 87, 94).

Como estratégia no imediato para os espaços de participação institucionalizados, indicamos que devem ser colocadas em pauta a defesa da gestão pública estatal, além de 
reconhecer a participação como direito social, questionar a desigualdade da ordem social vigente e produzir politização dos sujeitos sociais. Complementando, Krüger (2008, p. 89) considera que ao ser implementada a diretriz da participação da comunidade na Carta Constitucional através dos espaços institucionalizados, não ocorreram mudanças de paradigmas, porém, "se abriu espaço para os segmentos populares começarem a debater a agenda pública estatal". 0 sentido de participação ganhou o status de um bem público que permeia as relações sociais e a gestão pública em direção ao atendimento das necessidades sociais.

No pensamento de Bravo (2009, p. 464), a concepção de participação defendida está relacionada à ampliação dos sujeitos sociais na democratização do Estado brasileiro, tendo no horizonte uma nova relação Estado-Sociedade, com a ampliação dos canais de participação direta. No entanto, em contraposição a esta perspectiva democratizadora emergiu no Brasil na década de 1990, com o Programa de Reforma do Estado, uma proposta de administração gerencial para o serviço público (BRESSER-PEREIRA, 2010). Assim, no âmbito das políticas sociais o Estado deixa de ser o grande responsável pela execução, financiamento e regulação dos serviços públicos.

A parceria do setor público, com o setor privado e o chamado setor social (filantrópicos e as organizações da sociedade civil) passa a ser valorizada e demandada. Com isso, há o incentivo da participação, mas no sentido de parceria e de colaboração com a sociedade civil para execução dos serviços públicos. Sendo assim, está se constituindo um outro tipo de participação que se orienta por uma ideia de política como troca e colaboração entre governantes e governados (NOGUEIRA, 2005). Avaliamos ser possível chamar esse conjunto de práticas e ações de participação gerencial.

Entre os motivos para a sustentação dessa participação gerencial (M ONTANO, 2007, p. 23) estão os seguintes: a oferta de políticas que sociais que não são universais, a retirada da responsabilidade do capital e a criação por um lado de "uma imagem de transferência de responsabilidades e por outro a partir da precarização [...] da ação estatal e do terceiro setor, uma nova e abundante demanda lucrativa para o setor empresarial".

A participação gerencial não se descola de temas caros das lutas democrático populares, pois metamorfoseou seus conceitos. Defende que com a redução do papel do Estado (ficando com as áreas em que o mercado está ausente) e a ampliação de parcerias, haverá 0 aprofundamento da democracia e da cidadania. Assim, o administrador público 
profissional terá condições efetivas de gerenciar com eficiência às agências públicas, tendo o controle dos resultados.

Sem se desvincular de uma lógica de gestão pública gerencial, vivemos partir de 2016 uma conjuntura regressiva em termos de política social e econômica no Brasil. Para responder a crise adotaram-se medidas políticas de austeridade fiscal que estão colocando em risco os fundamentos democrático-populares da Constituição. As medidas nacionais e experiências internacionais de desconstitucionalização dos sistemas de proteção social públicos e universais, particularmente no Brasil, colocam renovados desafios aos espaços de participação popular.

Aqui se destacam as resistências que os Conselhos Nacionais das políticas sociais juntamente a uma série de movimentos sociais, têm utilizado para o enfrentamento ao desmonte dos serviços públicos: participação e organização de manifestações públicas, recomendações, resoluções, moções, notas e vídeos nas redes sociais, mas seu impacto diante das medidas de austeridade fiscal está sendo pouco significativas.

$\mathrm{Na}$ mesma medida, os espaços participativos institucionalizados das esferas subnacionais estão sendo atingidos por reiteradas tentativas do Poder Executivo de acabar com o papel deliberativo, tornando-os marginais nos processos de tomada de decisão, ignorando suas manifestações e resoluções. A resistência aos programas de austeridade e a defesa dos marcos constitucionais precisam contar com o fortalecimento dos espaços institucionalizados de participação popular e, sobretudo, de organização sociopolítica dos trabalhadores e dos movimentos sociais em torno de agendas que articulem a defesa da saúde pública estatal, entrelaçada aos demais direitos sociais e direitos da classe trabalhadora, de modo a alterar à correlação de forças presentes na atual conjuntura (KRÜGER; OLIVEIRA, 2018).

Na sequência, após uma breve caracterização do Conselho de Assistência Social, procuraremos apontar possíveis funções de acordo com a legislação profissional e as funções que entendemos ser pertinente ao profissional de Serviço Social desempenhar enquanto representante do gestor nos Conselho de Assistência Social.

\section{O Assistente Social nos Conselhos de Assistência Social}

A Política de Assistência Social é política social pública, não contributiva, contemplando junto com a Saúde e a Previdência Social o sistema de Seguridade Social a 
partir de 1988. Entretanto, foi em 1993 que essa política teve sua respectiva Lei Orgânica aprovada, que vai indicar sua operacionalização. Ao constituir-se como política pública, a Assistência Social também passa a ser acompanhada por canais institucionais de participação.

A Lei Orgânica de Assistência Social - LOAS (LEl n 8742/93), em seu artigo 5º prevê a participação da população no controle das ações em todos os níveis, através de instâncias representativas e também a primazia e responsabilidade do Estado na condução dessas ações (BRASIL, 1993). Com isso, a participação na Assistência Social, pela primeira vez passa a ser regulamentada através de uma legislação específica na área, em conjunto com a descentralização político-administrativa.

No caso da Política de Assistência Social, os conselhos ${ }^{4}$ possuem caráter paritário, ou seja, sua composição é de $50 \%$ de representantes estatais e $50 \%$ de representantes da sociedade civil, sendo que este segmento se divide em entidades profissionais da área e usuários da respectiva política. Essa paridade no espaço conselhista impõe-se como um mecanismo de equilíbrio (físico dos seus integrantes) entre Estado e sociedade nas decisões a serem tomadas. Além disso, também é deliberativo, ou seja, suas ações "implicam atos decisórios de aprovação e devem ser expressos na forma de resoluções dos conselhos" (PINHEIRO; PAULA, 2012, p. 96).

Os conselhos, enquanto canais participativos se constituem em mais um lócus de atuação e exercício profissional do assistente social. Esses profissionais tem a possibilidade de organizar, acompanhar e assessorar os conselhos nas três esferas de governo, podendo se inserir tanto na representação do gestor ou sociedade civil. Além de conselheiro, o profissional de Serviço Social também pode atuar na assessoria, pesquisa, capacitação de conselheiros, organização de plenárias ou como observador (M ACHADO, 2015).

Diversos documentos inerentes ao exercício e a formação profissional do assistente social, fornecem subsídios para a participação e organização política, além de indicarem diretrizes para a participação política da classe trabalhadora. Entre eles estão, por exemplo,

\footnotetext{
${ }^{4}$ Conforme preconiza a LOAS no seu artigo $16^{\circ}$ (BRASIL, 1993), as instâncias deliberativas do Sistema Único de Assistência Social, de caráter permanente e composição paritária entre governo e sociedade civil são: Conselho Nacional de Assistência Social, os Conselhos Estaduais de Assistência Social, o Conselho de Assistência Social do Distrito Federal e os Conselhos Municipais de Assistência Social. Além disso, conforme o Art. 17 ${ }^{\circ}$, inciso II, parágrafo 4ํㅡ os Conselhos, com competência para acompanhar a execução da política de assistência social, apreciar e aprovar a proposta orçamentária, em consonância com as diretrizes das conferências nacionais, estaduais, distrital e municipais, de acordo com seu âmbito de atuação, deverão ser instituídos, respectivamente, pelos Estados, pelo Distrito Federal e pelos M unicípios, mediante lei específica.
} 
- Código de Ética Profissional de 1993, que trouxe diversos avanços em relação aos fundamentos teórico-metodológicos da profissão. Neste documento, preconiza-se o direito de 0 assistente social estender sua atividade desde a elaboração, gerenciamento até a execução das políticas sociais, além de contribuir na viabilização da participação da sociedade nas decisões institucionais (CONSELHO FEDERAL DE SERVIÇO SOCIAL, 1993).

A Lei de Regulamentação da Profissão de 1993, também aborda que entre as competências do profissional de Serviço Social estão a elaboração, implementação, avaliação e execução de políticas sociais, com participação da sociedade junto à órgãos públicos direta ou indiretamente (BRASIL, 1993).

No caso dos representantes do gestor, os conselheiros que representam esse segmento nos conselhos são aqueles profissionais indicados e nomeados diretamente pelo próprio gestor da política em cada esfera de governo, não passando como os demais segmentos por um fórum eletivo entre pares (CONSELHO NACIONAL DE ASSISTÊNCIA SOCIAL, 2006). O representante do gestor é o profissional que se vincula ao aparelho do Estado responsável pela gestão, nesse caso, da Política de Assistência Social. Com isso, "a depender da posição do gestor em relação aos espaços participativos, ocorre a indicação da sua representação, podendo ser mais técnica, política ou uma representação mais dotada ou mais isenta de poder de representação." (MACHADO; KRÜGER, 2017, p. 154).

Ser representante do gestor é conhecer os trâmites burocráticos da gestão, suas prioridades, seu orçamento, os critérios de repasse dos recursos e também atuar, tendo como pressuposto as necessidades sociais do município e pautar-se nas informações e nos indicadores sociais e econômicos. A partir desse conhecimento é que surge a oportunidade de trabalhar com a socialização das informações e a possibilidade de problematizar os elementos tradicionais e progressistas da cultura política brasileira. (M ACHADO, 2015).

Além disso, consideramos que ser conselheiro governamental não é somente participar de uma reunião ordinária mensal, mas cumprir uma função pública, ter capacidade técnica e poder de decisão sobre os assuntos que permeiam a política, como "aprovação de planos, gastos públicos, fiscalização e acompanhamento". (CONSELHO NACIONAL DE ASSISTÊNCIA SOCIAL, 2006). Em tese, ser representante do gestor é conhecer os recursos disponíveis e potenciais, fluxos de projetos entre as três esferas de governo, prazos de editais e licitações e normas dos órgãos de fiscalização como os Tribunais de Contas. É também tomar decisões em relação aos trâmites burocráticos que envolvem a 
gestão da respectiva política, é conhecer e socializar as informações que circulam nesse espaço deliberativo e executivo, como as pautas, atas, resoluções, normativas sobre a gestão técnica e orçamentária da política social e os instrumentos de gestão (Planos Plurianuais, agenda anual, relatórios de gestão, orçamento anual).

Dado este conjunto de funções que é eminentemente de direção política e executiva, o papel do profissional, como conselheiro representante do gestor, não se reduz a atividades burocráticas e rotineiras e, portanto, é este mais um espaço político estratégico de atuação e exercício profissional do serviço social no âmbito das políticas sociais.

O documento Parâmetros para Atuação de Assistentes Sociais na Política de Assistência Social, produzido coletivamente pela categoria, sob a coordenação do Conselho Federal de Serviço Social (2011) ressalta o compromisso ético, político e profissional dos assistentes sociais brasileiros na luta pela Assistência Social com vistas à garantia dos direitos das classes trabalhadoras, na defesa da radicalização da democracia, enquanto socialização da participação política e da riqueza socialmente produzida; no posicionamento em favor da equidade e justiça social, que assegurem universalidade de acesso aos bens e por meio de gestão democrática.

O documento apresenta as competências específicas dos assistentes sociais, no âmbito da política de Assistência Social e aqui destacamos apenas aquelas que se relacionam com os espaços institucionalizados de participação (CONSELHO FEDERAL DE SERVIÇO SOCIAL, 2011, p. 20, 24):

- Intervenção profissional voltada para inserção nos espaços democráticos de controle social e construção de estratégias para fomentar a participação, reivindicação e defesa dos direitos pelos usuários e trabalhadores nos Conselhos, Conferências e Fóruns da Assistência Social e de outras políticas públicas;

- Dimensão de gerenciamento, planejamento e execução direta de bens e serviços à indivíduos, famílias, grupos e coletividade, na perspectiva de fortalecimento da gestão democrática e participativa, capaz de produzir, intersetorial e interdisciplinarmente, propostas que viabilizem e potencializem a gestão em favor dos cidadãos;

- Participar nos Conselhos municipais, estaduais e nacional de Assistência Social na condição de conselheiro;

- Atuar nos Conselhos de Assistência Social na condição de secretário executivo; 
- Prestar assessoria aos conselhos, na perspectiva de fortalecimento do controle democrático e ampliação da participação de usuários e trabalhadores;

- Participar na organização, coordenação e realização de conferências municipais, estaduais e nacional de Assistência Social e afins.

O Serviço Social como profissão de nível superior, com formação teórica, técnica, ética e política, orientando-se por uma Lei de Regulamentação Profissional e um Código de Ética, tem nos espaços de participação institucionalizados uma gama de possibilidades de ação que podem se orientar pela perspectiva crítica de leitura da realidade e capacidade de identificação das respostas existentes no âmbito do Estado e da sociedade civil.

$\mathrm{Na}$ condição de conselheiro representante do gestor, o profissional tem um espaço privilegiado de atuação, no sentido de corresponder aos fundamentos do projeto éticopolítico e as competências indicadas acima. No entanto, essa é uma escolha técnica e política que não está isenta de inúmeros constrangimentos, que sofre implicações no âmbito das relações e interesses políticos da gestão municipal até a condição de trabalhador assalariado.

\section{A concepção de Participação do Assistente Social Representante do Gestor}

A seguir, apresentamos o entendimento e a compreensão dos assistentes sociais sobre a participação. Estes profissionais assistentes sociais responderam o questionário no momento em que atuavam nos Conselhos de Assistência Social como representantes do gestor em municípios de Santa Catarina.

Alguns profissionais atribuíram à participação os seguintes conceitos:

A capacidade dos sujeitos de livremente intervir no processo político social e econômico, pautando necessidades de forma não corporativa, promovendo a igualdade. Tal forma de participação é um limite aos conselhos, que institucionalizados, se tornam formalmente espaços de representação e criação de consenso. (questionário 7).

A participação se dá a partir do momento em que intencionamos em saber sobre a coisa pública. Temos que ter a oportunidade de conhecer os trâmites institucionais e espaços democráticos de discussão. Temos o direito de ter as questões explicadas de forma clara para termos a capacidade de opinar. Não basta simplesmente dizer que temos um conselho paritário e os não-governamentais ficar em desvantagem perante os 
governamentais. Participar é compreender, ter acesso a documentos, discutir, avaliar e deliberar o que é melhor para a população. (questionário 10).

Participação é um processo onde as pessoas se tornam sujeitos políticos, ou seja, exercem direitos políticos, diretamente relacionados à consciência de cidadão, onde estão postas as possibilidades de contribuir com os processos de mudanças e conquistas nas decisões da vida social. (questionário 11).

Essa compreensão de participação apontada pelos assistentes sociais, conselheiros representantes do gestor, direciona-se à uma perspectiva de que a participação é um direito social, um direito de entender e de intervir nos trâmites das decisões públicas. M esmo como espaço institucionalizado, é possível que os segmentos sociais sejam reconhecidos como sujeitos sociais, que podem agir não apenas de forma corporativa, ou buscando consenso, mas deliberar sobre ações para mudanças na vida social e na busca pela garantia e viabilização de direitos e igualdade. Por exemplo, o profissional número 10 aponta possibilidades de não deixar um fosso de qualificação entre conselheiros governamentais e não governamentais, fazendo aposta na informação e formação dos integrantes.

Outros profissionais compreendem e conceituam a participação a partir de uma perspectiva que chamamos de flexibilizadora, pois se afasta da radicalização democrática, apesar de manter uma retórica semelhante. A seguir, encontram-se algumas perspectivas apontadas pelos assistentes sociais participantes da pesquisa:

É o envolvimento de pessoas por alguma causa ou alguma coisa e elas tem que ter esclarecimento da importância dessa participação. (questionário 2).

Um processo democrático que auxilia o desenvolvimento e as escolhas. Estar presente nas decisões. Envolvimento dos cidadãos nas decisões. M omento de manifestação. Uma forma de se comunicar. Troca. (questionário 3).

Participação envolve a presença ativa e direta dos sujeitos e, em especial a participação nos conselhos implica em mediação de demandas coletivas. (questionário 9).

Envolvimento pessoal nas questões de ordem popular, políticas e sociais. A participação é a regra para a democracia, caso contrário não haverá espaço algum de tensionamento para os interesses da maioria. (questionário 12).

Constatamos que os profissionais, na mesma medida que reconhecem e acentuam a importância da democracia e da participação no conselho, também indicam que parece ser uma questão de interesse individual. Alguns assistentes sociais, pouco se distanciando de 
uma linguagem do senso comum, reconhecem que participação é um processo importante nas decisões políticas e atribuem a essa participação um sentido de troca e envolvimento das pessoas nas questões de ordem pública. Para os profissionais, participar é 0 envolvimento pessoal e a manifestação em questões, causas e decisões políticas e sociais. Apenas um deles fez referência de que a participação visa o interesse da maioria e outro considerou que a prática do conselho é uma mediação para atender demandas coletivas.

Nas respostas obtidas com a pesquisa, identificamos um assistente social representante do gestor que fala em uma verdadeira participação:

0 entendimento do assunto em pauta, podendo dar suas opiniões para novos horizontes, entendo que todas as experiências são válidas e enriquecedoras, por isso a participação de pessoas ativas nas representações é essencial para uma verdadeira participação. (questionário 1).

O sentido de participação para este profissional se vincula em compreender 0 assunto da pauta, emitir opinião sobre ela e ser ativo nas representações e com isso chegase a uma verdadeira participação. Qual é o sentido dessa verdadeira representação? Para além de ser uma experiência enriquecedora num local que se pode emitir opiniões o profissional parece esquecer da sua função pública e da função pública do conselho.

Este conjunto de falas dos profissionais de Serviço Social que procuram caracterizar e conceituar seu entendimento de participação, revela uma grande distância dos fundamentos do Projeto Ético-Político da profissão que se forjou na década de 1990. Igualmente revela uma distância da participação, enquanto um dos fundamentos das políticas sociais reconhecidas em 1988.

As falas dos profissionais não expressam nenhuma diferença ou particularidade, enquanto ocupante de uma cadeira no Conselho Municipal de Assistência Social, como representante do gestor. Os desafios e a responsabilidade pública do desempenho dessa função para implementar a política pública de Assistência Social não ganhou relevância ou preocupação dos assistentes sociais na resposta do questionário.

Entretanto, entendemos que a participação deve ir um além de questões que envolve a troca, a expressão de opiniões e o envolvimento pessoal. Participar é um processo que envolve a socialização da política, a universalidade do acesso a bens e serviços, a garantia de direitos, ou seja, vai além do envolvimento e das mediações. Nesse sentido, é necessário que a participação dos sujeitos exerça influência sobre as decisões a serem 
tomadas nos espaços de participação política, com vistas a responder necessidades públicas e coletivas.

0 assistente social enquanto profissional atuante nesses canais deliberativos, independente do segmento que representa tem o papel de "fomentar a participação dos usuários, exercer o controle democrático por meio de comissões e articular-se a outros conselheiros e movimentos sociais para que as decisões tomadas nos conselhos resultem em políticas democráticas" e com isso não se torne "um burocrata das demandas localizadas" (NEVES; SANTOS; SILVA, 2012, p. 177).

Os conceitos de participação relatados pelos profissionais do Serviço Social não se vinculam às referências que a profissão tem no Código de Ética de 1993 e nem nas atribuições e competências que estão na Lei de Regulamentação Profissão do mesmo ano. A formação generalista com grande direcionamento para atuação do assistente social nas políticas públicas, indicadas nas Diretrizes Curriculares da Associação Brasileira de Ensino e Pesquisa em Serviço Social de 1996, no qual a participação do profissional e a mobilização dos usuários e trabalhadores para também integrar os espaços de decisão das políticas sociais, não foi objeto de consideração nos questionários respondidos.

No conjunto das falas podemos afirmar que os assistentes sociais representantes do gestor compreendem a participação como um importante processo democrático que perpassa seu espaço de exercício profissional, mas que o sentido de responsabilidade pública de um gestor não foi mencionado. Também verificamos que alguns sujeitos da pesquisa entendem que participar é essencialmente deliberar sobre certas questões, em especial questões burocráticas. Além disso, a pesquisa também revelou interação e envolvimento, mas foram poucos os profissionais que apontaram o conselho como um espaço heterogêneo onde circulam interesses diferentes e polêmicos.

Os traços da cultura política perpassados pela centralização do poder, autoritarismo e clientelismo sequer foram considerados nos relatos sobre o entendimento de participação nas políticas sociais. E a participação como tema representativo da gestão pública democrática, não ganhou este status na pesquisa empírica, o entendimento não avançou para além da participação passiva e instrumental ou a óbvia perspectiva da semântica vernacular - de tomar parte.

Entretanto, a participação é um processo que não se resume a deliberações, envolve a compreensão dos fatos, as necessidades dos sujeitos envolvidos e é um processo 
de reconhecimento de direitos, numa sociedade marcada pela desigualdade socioeconômica. Mas a este processo estão associados os possíveis constrangimentos e/ou ameaças que envolvem a condição de trabalhador assalariado do assistente social. Situação que não foi mencionada em nenhum dos questionários.

\section{Considerações Finais}

Com a Constituição de 1988, a participação social torna-se institucional. Essa institucionalidade emerge com os espaços deliberativos de políticas sociais, considerados uma inovação no campo da democracia tendo em vista permitirem a paridade entre Estado e sociedade civil. Entretanto, apesar de se constituírem em um avanço no campo da democracia, esses colegiados são perpassados por uma série de contradições, onde imperam uma disputa de interesses.

É também em meio a essa contradição que envolve o conselho que 0 assistente social tem a oportunidade de inserir-se na atualidade enquanto profissional. A ocupação deste espaço representa um alargamento das fronteiras do exercício profissional e das potencialidades que o assistente social representante do gestor tem de orientar a direção das políticas sociais. Destacamos ainda que, concomitantemente à emergência desses espaços, legislações inerentes à profissão de Serviço Social emergem e colocam a participação social como um processo intrínseco ao exercício profissional.

Conforme verificamos nos dados apresentados, os assistentes sociais representantes do gestor nos conselhos compreendem a necessidade da participação nesse espaço de representação política onde se inserem enquanto conselheiros e profissionais. São trazidas questões referentes à deliberação, envolvimento e correlação de forças, entretanto, muitas lacunas ficaram entreabertas sobre suas respectivas concepções de participação, desencontrando-se do que está previsto nas legislações que respaldam a profissão.

Nos conselhos, onde circulam uma série de informações, é necessário que os profissionais tenham atrelados ao seu exercício profissional a concepção de participação orientada aos princípios da legislação profissional. O Código de Ética é uma dessas leis e contribui inclusive nesse propósito sendo um de seus princípios fundamentais a "defesa do aprofundamento da democracia enquanto socialização da participação política e da riqueza socialmente produzida" (CONSELHO FEDERAL DE SERVIÇO SOCIAL, 1993). Entretanto, apesar 
desse documento ter sido abordado diversas vezes no contexto geral da pesquisa pelos assistentes sociais, apenas três profissionais conseguiram trazer esse conceito de participação.

É fundamental que a participação política se direcione aos princípios de radicalização da democracia, da socialização da riqueza e do poder político, da universalidade de acesso aos bens e serviços e sua gestão democrática, indo ao encontro do Projeto Ético-Político da profissão. Nessa perspectiva, o assistente social pode ser um articulador, um potencializador, um assessor e educador político nos espaços colegiados de participação das políticas sociais.

No entanto, a condição de representante do gestor nos conselhos por parte dos assistentes sociais não foi destacada em sua particularidade. Ficamos com a impressão de que as falas dos profissionais não teriam diferenças substanciais se estivessem no conselho, representando qualquer um dos outros segmentos sociais. Por isso, avaliamos a necessidade de novas pesquisas mais sistemáticas tratando desse espaço de trabalho do Serviço Social.

\section{Referências}

ALM EIDA, Débora Cristina Rezende de. Os desafios da efetividade e o estatuto jurídico da participação: a Política Nacional de Participação Social. Sociedade e Estado, Brasília, v. 32, n. 3, p. 649-679, set./dez. 2017. DOI 10.1590/s0102-69922017.3203005. Acesso em: 13 maio 2018.

ASSOCIAÇÃO BRASILEIRA DE ENSINO E PESQUISA EM SERVIÇO SOCIAL. Diretrizes gerais para o curso de Serviço Social: (Com base no Currículo M ínimo aprovado em Assembléia Geral Extraordinária de 8 de novembro de 1996). 1996. Disponível em: http://www.cressrs.org.br/docs/Lei_de_Diretrizes_Curriculares.pdf. Acesso em: 13 maio 2018. BEHRING, Elaine; BOSCHETTI, Ivanete. Política social: fundamentos e história. São Paulo: Cortez, 2006.

BRASIL. [Constituição (1988)]. Constituição da República Federativa do Brasil. Brasília: Senado Federal, 2010.

BRASIL. Decreto no 8.243, de 23 de maio de 2014. Institui a Política Nacional de Participação Social - PNPS e o Sistema Nacional de Participação Social - SNPS, e dá outras providências. 2014. Disponível em: http://www.planalto.gov.br/ccivil_03/_ato2011-2014/2014/decreto/d8243.htm. Acesso em: 4 out. 2016.

BRASIL. Lei n ${ }^{8662 / 93}$ de 7 de junho de 1993. Dispõe sobre a profissão de Assistente Social e dá outras providências. Disponível em: http://www.planalto.gov.br/ccivil_03/leis/L8662.htm. Acesso em: 15 jan. 2017. 
BRASIL. M inistério do Desenvolvimento Social e Combate à Fome. Norma operacional básica do Sistema Único de Assistência Social. Brasília: MDSCF, 2005.

BRAVO, Maria Inês Souza. 0 trabalho do assistente social nas instâncias públicas de controle democrático. In: CONSELHO FEDERAL DE SERVIÇO SOCIAL; ASSOCIAÇÃO BRASILEIRA DE ENSINO E PESQUISA EM SERVIÇO SOCIAL (org.). Serviço social: direitos sociais e competências profissionais. Brasília: CFESS: ABEPSS, 2009. p. 393-410.

BRESSER-PEREIRA, Luiz Carlos. Democracia, estado social e reforma gerencial. Revista de Administração de Empresas, São Paulo, v. 50, n. 1, p. 112-116, jan./mar. 2010. DOI: http://dx.doi.org/10.1590/S0034-75902010000100009. Disponível em: http://www.scielo.br/pdf/rae/v50n1/a09v50n1.pdf. Acesso em: 17 maio 2018.

CÂMARA DOS DEPUTADOS. Projeto de Decreto Legislativo (SF) $n^{\circ} 147$, de 2014. Susta a aplicação do Decreto no 8.243, de 23 de maio de 2014, que institui a Política Nacional de Participação Social - PNPS e o Sistema Nacional de Participação Social - SNPS, e dá outras providências. 2014a. Disponível em: https://www25.senado.leg.br/web/atividade/materias//materia/118766. Acesso em: 4 out. 2016.

CÂMARA DOS DEPUTADOS. Projeto de Decreto Legislativo PDC 1491/2014. Susta a aplicação do Decreto no 8.243, de 23 de maio de 2014, que institui a Política Nacional de Participação Social PNPS e o Sistema Nacional de Participação Social - SNPS, e dá outras providências. 2014b. Disponível em: http:// www.camara.gov.br/proposicoesWeb/ fichadetramitacao $?$ idProposicao $=617737$. Acesso em: 20 maio 2018.

CONSELHO FEDERAL DE SERVIÇO SOCIAL. Código de ética profissional do assistente social. 1993. Disponível em: http://www.cfess.org.br/arquivos/CEP_CFESS-SITE.pdf. Acesso em: 8 jan. 2017.

CONSELHO FEDERAL DE SERVIÇO SOCIAL. Parâmetros da atuação do Assistente Social na Política de Assistência Social. 2011. Disponível em: http://www.cfess.org.br/arquivos/Cartilha_CFESS_Final_Grafica.pdf. Acesso em: 13 dez. 2017.

CONSELHO NACIONAL DE ASSISTÊNCIA SOCIAL. Resolução n- 237 de 14 de dezembro de 2006. Diretrizes para a estruturação, reformulação e funcionamento dos Conselhos de Assistência Social. Diário Oficial da União: seção 1, Brasília, DF, n. 246, 26 dez. 2006. Disponível em: http://www.prefeitura.sp.gov.br/cidade/secretarias/upload/assistencia_social/comas/arquivos/ conferencia_municipal/2011/ResolucaoCNASno237de14dedezembrodē2006.pdf. Acesso em: 15 nov. 2017.

COUTINHO, Carlos Nelson. Contra a corrente: ensaios sobre democracia e socialismo. 2. ed. São Paulo: Cortez, 2008.

KRÜGER, Tânia Regina. As conferências de saúde e os planos municipais de saúde: considerações sobre o significado da participação popular em Santa Catarina. Florianópolis: DIOESC, 2012.

KRÜGER, Tânia Regina. Participação da comunidade: 20 anos de diretriz constitucional. Revista Emancipação, Ponta Grossa, v. 8, n. 2, p. 75-90, 2008. DOI http://dx.doi.org/10.5212/Emancipacao.v.8i2.075090. Disponível em: http://www.uepg.br/emancipacao. Acesso em: 12 jan. 2018. 
KRÜGER, Tânia Regina; M ACHADO, Cristiane Canez. 0 tema da participação e as bases teóricopolíticas do Serviço Social. Textos \& Contextos, Porto Alegre, v. 14, n. 1, p. 49 - 61, jan./jun. 2015. DOI 10.15448/1677-9509.2015.1.20174. Disponível em:

http://revistaseletronicas.pucrs.br/ojs/index.php/fass/article/view/20174/13308. Acesso em: 10 mar. 2018.

KRÜGER, Tânia Regina; OLIVEIRA, Andréia. Trinta anos da Constituição Federal e a participação popular no SUS. Argumentum, Vitória, v. 10, n. 1, p. 57-71, jan./abr. 2018. DOI http:// 10.18315/argumentum.v10i1.18621. Disponível em http:// periodicos.ufes.br/argumentum/article/view/18621/13181. ISSN 2176 9575. Acesso em: 13 ago. 2018.

M ACHADO, Cristiane Canez. Os Assistentes Sociais nos Conselhos de Assistência Social como representantes do gestor. 2015. Dissertação (M estrado em Serviço Social) - Universidade Federal de Santa Catarina, Santa Catarina, 2015.

M ACHADO, Cristiane Canez; KRÜGER, Tânia Regina. Os Assistentes Sociais nos conselhos de Assistência Social como representantes do gestor. M OSER, Liliana; M ANFROI, Vania M aria (org.). Questão Social e Direitos Humanos, Florianópolis, 2016. v. 1. p. 167-195.

M ACHADO, Cristiane Canez; KRÜGER, Tânia. Regina. O Assistente Social representante do gestor no Conselho de Assistência Social. Argumentum, Vitória, v. 9, n. 1, p. 150-163, jan./abr. 2017. DOI https://doi.org/10.18315/argum.v9i1.13328. Disponível em: http://www.periodicos.ufes.br/argumentum/article/view/13328/10937. Acesso em: 13 maio 2018.

M ONTANO, Carlos. Terceiro setor e questão social: crítica ao padrão emergente de proteção social. 4. ed. São Paulo: Cortez, 2007.

NETTO, Jose Paulo. Democracia e transição socialista. Belo Horizonte: Oficina de Livros, 1990.

NEVES, Ângela Vieira; SANTOS, Cláudia de Oliveira Vicente; SILVA, Suellem Henriques da. Conselhos M unicipais de Assistência Social: novas competências para o trabalho do assistente social. Revista katálysis, Florianópolis, v. 15, n. 2, p. 173-181, jul./dez. 2012. DOI: http://dx.doi.org/10.1590/S1414-49802012000200003. Disponível em: http://www.scielo.br/scielo.php?pid=S1414-49802012000200003\&script=sci_abstract\&tlng=pt. Acesso em: 13 dez. 2017.

NOGUEIRA, Marco Aurélio. Um estado para a sociedade civil: temas éticos e políticos da gestão democrática. 2. ed. São Paulo: Cortez, 2005.

PAIVA, Beatriz Augusto de; ROCHA, M irella; CARRARO, Dilceane. Participação popular e assistência social na América Latina: teses, contextos dilemas. In: STUCHI, Carolina Gaba; PAULA, Renato Francisco Santos; PAZ, Rosângela Dias Oliveira (org). Assistência social e filantropia: cenários contemporâneos. São Paulo: Veras Editora, 2012. p. 271-288. (Coleção coletâneas).

PINHEIRO, Márcia M aria Biondi; PAULA, Renato Francisco dos Santos. Controle social no Brasil pós-SUAS: tendências e perspectivas. In: STUCHI, Carolina Gaba; PAULA, Renato Francisco Santos; PAZ, Rosângela Dias Oliveira (org.). Assistência Social e filantropia: cenários contemporâneos: São Paulo: Veras Editora, 2012. p. 89-107. (Coleção coletâneas). 